\title{
アテトーゼ型脳性麻痺を伴った頝部脊髄症の 手術的治療
}

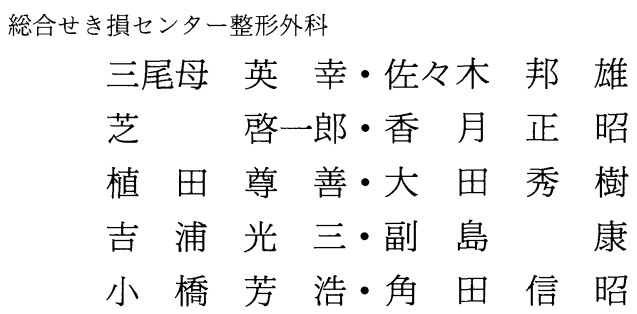

\section{Surgical Treatment of Cervical Spondylotic Myelopathy Associated with Athetoid Cervical Palsy}

by

\section{Hideyuki Miomo, Kunio Sasaki, Keiichiro Shiba, Masaaki Katsuki Takayoshi Ueta, Hideki Ota, Kouzou Yoshiura, Yasushi Soejima Yoshihiro Kohashi and Nobuaki Tsunoda \\ Department of Orthopaedic Surgery Spinal Injuries Center}

Operative treatment was performed on five patients with cervical spondylotic myelopathy associated with athetoid cerebral palsy. Four patients were treated by an anterior and posterior spinal fusion and only one patient was treated by laminectomy and posterolateral fusion, because the deformity of the cervical spine was wide.

The halo-brace was used in each patient from preoperative days in order to immobilize the cervical spine and almost good bony fusion was obtained in all, but two patients showed a kyphotic change of the cervical spine. Symptoms improved in all five patients, but a little.

We think that an anterior and posterior spinal fusions with modified Rogers' method is a good surgical treatments to obtain a good bony fusion for these patients.

\section{は じめに}

アテトーゼ型脳性麻痺患者では，そのアテトーゼ運 動のために比較的若年者で頝椎変化を起こし，难椎症 性脊髄症をきたすことがある。その診断は困難で手術 方法，術後の外固定についても問題となりやすい.

今回私たちは, 昭和 56 年より現在まで当センターて 手術的治療を行ってきたアテトーゼ型脳性麻痺を伴う 頚部脊髄症 5 例について，報告する。
対象および手術方法

症例は 5 例で男 4 例, 女 1 例, 年令は 27 才から 45 才 までで平均 35 才である.症状発現より当科受診までの 期間は 7 力月から 8 年で, follow-up 期間は 5 力月から 4 年 6 力月, 平均 2 年 1 力月である（表 1 ).

Halo-brace を術前より装着した. 手術は一期的な前 方および後方固定術を行ったもの 4 例で，そのうち 2 例に Rogers 変法（棘突起間締結十骨移植）を行った。 罹患椎間が 5 椎間にわたった 1 例に laminectomy と Robinson 法による後側方固定術を行った.術後に外固 
定として Halo-brace を平均 15.6 週間装着した（表 2 ). 症状発現に関与していると考えられた責任椎間の 確認は, Myelogram, CT, などのレントゲン診断によ り行った。

表 1 症 例

\begin{tabular}{ccccl}
\hline \hline Case & Age & Sex & $\begin{array}{l}\text { Period from onset } \\
\text { to admission }\end{array}$ & Follow up \\
\hline 1 & 27 & $\mathrm{M}$ & $2 \mathrm{yrs}$ & $4.5 \mathrm{yrs}$ \\
2 & 29 & $\mathrm{M}$ & $3 \mathrm{mos}$ & $1 \mathrm{y}$ \\
3 & 38 & $\mathrm{~F}$ & $8 \mathrm{yrs}$ & $3.5 \mathrm{yrs}$ \\
4 & 45 & $\mathrm{M}$ & $7 \mathrm{mos}$ & $1 \mathrm{y}$ \\
5 & 36 & $\mathrm{M}$ & $7 \mathrm{mos}$ & $5 \mathrm{mos}$ \\
\hline
\end{tabular}

表 2 手術方法とハローブレイスの装着期間

\begin{tabular}{|c|c|c|}
\hline Case & Treatment & $\begin{array}{l}\text { Duration of } \\
\text { Halo-Brace }\end{array}$ \\
\hline 1 & $\begin{array}{l}\mathrm{PSF}(\mathrm{C} 3-5) \\
\mathrm{ASF}(\mathrm{C} 3-5)\end{array}$ & $15 w$ \\
\hline 2 & $\begin{array}{l}\text { PSF }(C 2-5) \quad(R) \\
\text { ASF }(C 3-5)+\text { plating }\end{array}$ & $14 \mathrm{w}$ \\
\hline 3 & $\begin{array}{l}\text { Laminectomy (C } 3-7) \\
\operatorname{PLF}(\mathrm{C} 2-\mathrm{T} 1) \text { (Robinson) }\end{array}$ & $19 \mathrm{w}$ \\
\hline 4 & $\begin{array}{l}\text { ASF }(C 3-5) \\
\text { PSF }(C 3-6)\end{array}$ & $16 \mathrm{w}$ \\
\hline 5 & $\begin{array}{l}\text { ASF }(C 3-4) \\
\text { PSF }(C 3-4) \text { (R) }\end{array}$ & $14 \mathrm{w}$ \\
\hline
\end{tabular}

$\mathrm{R}$ : Rogers' modified
症

例

Case $3: 38$ 才，女性.

8 年前より四肢のシビレ感出現し, 上肢のシビレ感, 下肢の脱力感も次第に現われる.歩行不能となり来院。 四肢の腱反射元進し, 病的反射を認める. $\mathrm{X}$ 線上 $\mathrm{C}_{3-7}$ の変性が著るしく, 骨性 canal も narrow である.ミエ ログラムでも同部の dura の狭小化, $\mathrm{C}_{5 / 6}$ のブロックを 認める. 手術は $\mathrm{C}_{3-6}$ の椎弓切除術と $\mathrm{C}_{2}-\mathrm{T}_{1}$ の RobinSon 法による後側方固定術を行った. 術後 19 週間 Halo-brace を装着した。現在一部を除き骨癒合し, 椎 体も spoutaneous fusion している.術後シビレ感減少 し，つたい歩き可能となった。 JOA scoreで判定する と7点から 9 点であった（図 1 ).

Case $4: 45$ 才, 男性.

1 年前より両下肢の脱力感出現し歩行不能となる。 四肢の腱反射六進し, 病的反射を認める。 $\mathrm{C}_{3 / 4}, \mathrm{C}_{4 / 5}$ の instability と $\mathrm{C}_{5 / 6} \operatorname{disc}$ の狭小化があり, ミエログラム で $\mathrm{C}_{3 / 4}, \mathrm{C}_{4 / 5}, \mathrm{C}_{5 / 6}$ の前方圧排像を認める. 手術は $\mathrm{C}_{3-5}$ と $\mathrm{C}_{5 / 6}$ の前方固定術と $\mathrm{C}_{3-6}$ の後方固定術を行った。 $\mathrm{C}_{3-6}$ で後弯変形を生ずるも, 骨癒合良好で, 杖にて歩 行可能となった。 JOA scoreでは 6 点から 8 点であっ. た(図 2 ).

Case 5:36才, 男性。

約 7 力月前より右上下肢の脱力感と歩行障害が出現 する。四肢の腱反射の亢進と右手指筋力低下を認めた。 $\mathrm{C}_{3 / 4}$ の disc の狭小化とミエログラムでも同部の前方よ

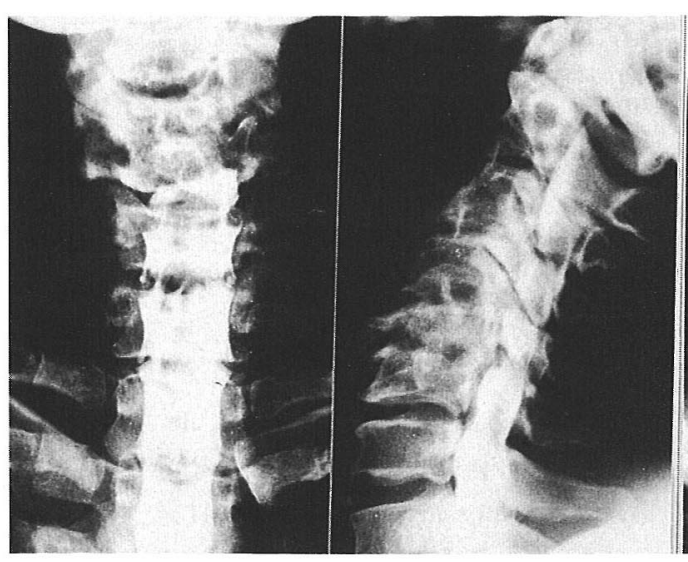

Myelo.

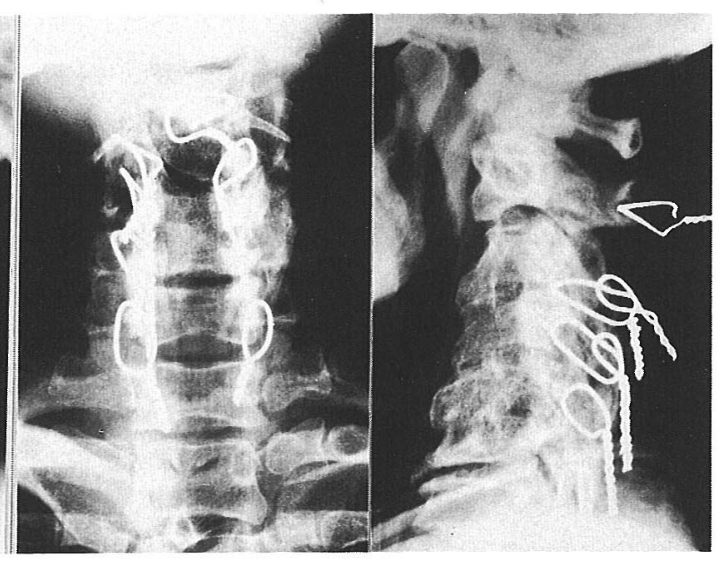

3 years after op.

図 1 Case 3. $C_{3-6}$ の椎弓切除術と $C_{2}-T_{1}$ の Robinson 法による後側方固定術を行った。 $C_{2 / 3}$ 以外はほぼ骨癒合した。 


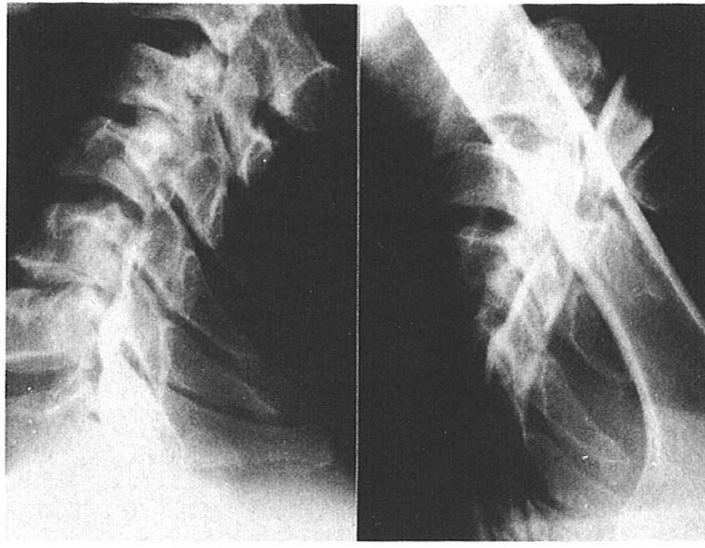

Myelo.

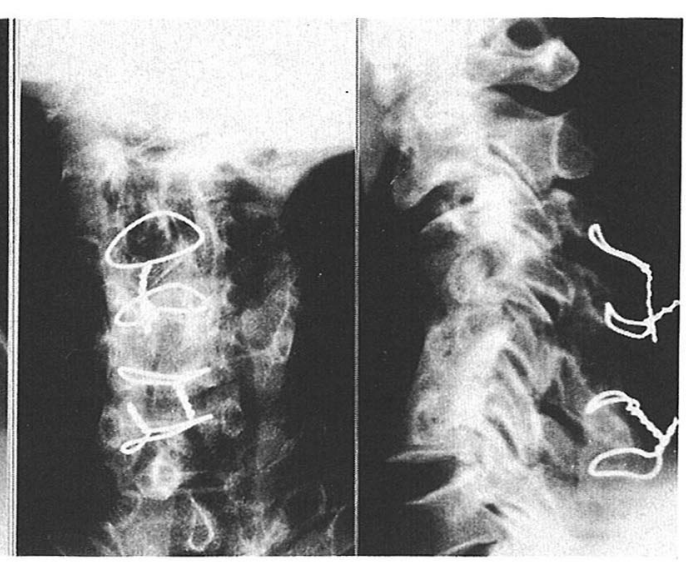

1 year later

図 2 Case $4 \mathrm{C}_{3-5}$ と $\mathrm{C}_{5 / 6}$ の前方および後方固定術を行った。 $\mathrm{C}_{4 / 5}$ で後弯変形生ずるも骨癒合完成.

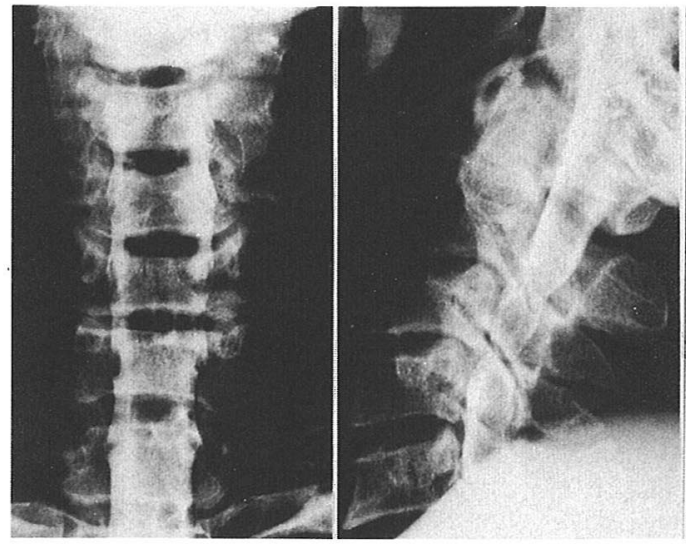

Myelo

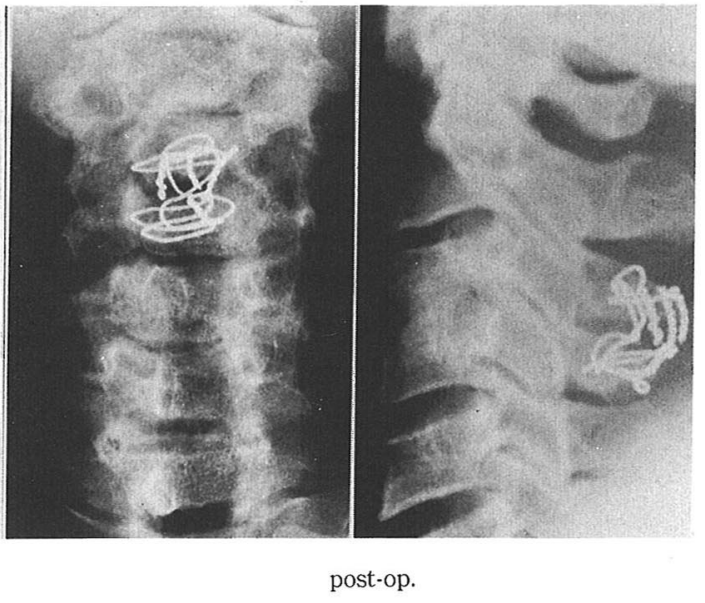

post-op.

図 3 Case $5 \mathrm{C}_{3 / 4}$ の前方および後方固定術 (Rogers 変法) を行い良好な骨癒合を得た。

りの圧排が存在した。手術は $\mathrm{C}_{3 / 4}$ の前方固定術と Rogers 変法の後方固定術を行った。 骨瘾合, アライメ ント共に良好で, 歩行状態も改善した。 JOA scoreで は 11 点から 13 点であった（図 3 ).

\section{結果}

責任椎間は $\mathrm{C}_{3 / 4}, \mathrm{C}_{4 / 5}$ レベルに多く, 罹患椎間が 4 椎 間以上の多椎間にわたった症例も2 例存在した(図 4 ). 症状の改善度は JOA score で判定した。 全例に改善 は得られたが, 改善率 (平林法) では $50 \%$ 以上 1 例, 25〜 $49 \% 1$ 例, $25 \%$ 以下が 3 例, 平均 $27.5 \%$ と低い
值であったＸ線学的変化では多椎間固定例で一部の non-union が存在したが, ほぼ全例に良好な骨癒合が得 られた. Rogers 法を用いた 2 例では良好なアライメン トが得られたが, 多椎間固定の 2 例で後弯変形を認め た.

Halo-brace による合併症としては, pinの loosening 3 例, pin 刺入部の感染 2 例, 術前に Ring の逸脱が 1 例存在した. loosening は装着後平均 11 週で発生した。 このような合併症は適切な処置でその後とくに問題な く経過した。 
$\mathrm{X}$ 線学的病変部位

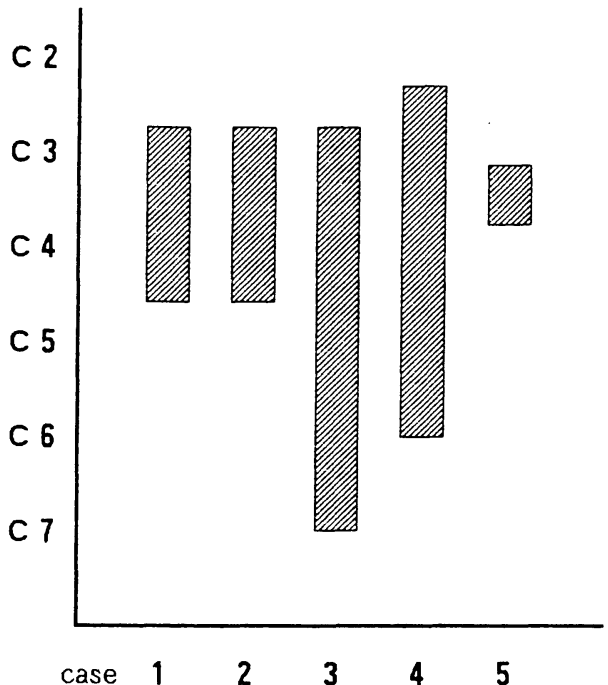

図 $4 \mathrm{C}_{3-4}$ に病変部が多い.

\section{考察}

アテトーゼ型脳性麻痺を伴った頝髄症の診断治療は 困難なことが多い. 手術的治療として以前は椎弓切除 術を行った症例も報告されているが3), 椎弓切除術は一 時期の症状の改善はあっても後に頝椎の不安定性を生 じ症状が再発しやすい" . 最近では前方固定術と外固定 が行われることが多く5) 良好な成績を得ることも多いが， 一部には，移植骨の圧潰や non-union となったという 報告もある ${ }^{4)}$. 私たちはより一層の強固な内固定を得る ために多椎間障害例を除き，前方および後方固定術を 行った ${ }^{2)}$.とくに棘突起間をワイヤーで締結する Rogers 変法を行った症例では, 共に良好な骨瘺合, アライメ 一トを得, 強固な内固定として本法は有効な術式と思 われるが, 後屈で retro-slip の強い症例には適応に十分 注意を要す。外固定には，グリソン牽引のような緩徐 な固定が有効だとする説6)もあるが, 強固な固定, 術後 のリハビリなどの問題を考えると, halo-brace の方が
よいと思われるが11 しかしこの外固定も呈示した症例て 分かるように決して完全な固定ではなく，また pinの loosening などの問題もあり,十分な注意を必要とする. 手術による症状の改善は本疾患では一般の頝髄症より も劣っていたが，基礎に脳性麻瘏が存在するために， JOA の判定基準だけで単純に判定，検討することに無 理があると思われる。

\section{参 考 文 献}

1）朝妻孝仁・他：脳性麻痺に合併した頚髄症の 2 手術 例. 整形外科, $37: 1451-1458,1986$.

2）権藤英資・他：アテトーゼ型脳性麻疩に伴う頚部脊 椎症性脊髄症の手術的治療の経験. 中部整災誌, 26 ： 77-81, 1983.

3) Levine, R. A et al.: Cervical spondylosis and dyskinesis. Neurology 20: 1194-1199, 1970.

4) Nishihara, N.: Surgical treatment of cervical spondylotic myelopathy complicating athetoid cerebral palsy. J. Bone Joint Surg. 66-B : 504-508, 1984.

5）大木 勲・他：アテトーゼ型脳性麻痺に合併して発 生した頚部脊椎症性脊䯣症の手術症例の検討. 臨整外, $19: 425-433,1984$.

6）手束昭㸝・他：成人脳性麻痖における cervical radiculo-myelopathy の経験. 臨整外, $13: 585-593$, 1978.

\section{質 問琉球大学 高良 宏明}

最近, 私はアテトーゼ型の脊髄症に対して, 除圧・ 固定との観点を捨てて，むしろ除圧とともに動かし， ある程度の制動効果で stability を獲得するとの考えか ら脊柱管拡大術を試みている. 先生の症例の中に多椎 間固定のためにその上下椎間に病変が出現した例はな かったでしようか.

\section{解 答 脊損センター 三尾母英幸}

固定椎間の上下椎間の不安定性の出現は特にアテト 一ゼ型脊髄症では出現しやすいということが予想され るが,われわれの症例でも follow 期間は短いが不安定 性をきたしたものが存在します。しかし症状の再発, 悪化は現在のところ認めていません。 